\title{
Gallbladder Polyp
}

National Cancer Institute

\section{Source}

National Cancer Institute. Gallbladder Polyp. NCI Thesaurus. Code C3909.

A polypoid tumor that arises from the gallbladder and projects into the lumen. This category includes adenomas and hyperplastic polyps. 